\section{An Outsider's Guide to Real Business Cycle Modeling}

\section{Joseph A. Ritter}

One exhibits understanding of business cycles by constracting a model in the most literal sense: a fully articulated artificial economy which behaves through time so as to imitate closely the time series behavior of actual economies.

Robert E. Lucas (1977)

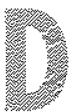
uring the last decade, guided by Lucas principle, the real business cycle (RBC) model has become a standard tool for a large share of macroeconomists. The tool has found such widespread applicability that proponents of this approach to macroeconomic modeling (and those with proper sensitivity training) now prefer a more generic label: computable dynamic general equilibrium model. Other demographic groups often regard the customs and rituals of RBC proponents with some degree of bafflement. The goal of this articte is to dispel some of the aura of mystery that surrounds-from an outsiders point of view-the specification, calibration, solution and evaluation of RBC mod els.' It is thus concerned more with the "hows" of RBC modeling than with the "why's" (or, for that matter, the "why not's")? Broader introductions to real business cycle modeling can be found in Blanchard and Fischer (1989, chapter 7), McCallum (1989), Plosser (1989) and Stadler (1994). The pioneering papers are Kydland and Prescott (1982) and Long and Plosser (1983).

Three criteria have guided the modelbuilding process an the RBC literature.
(1) Decisions of firms and consumers should be derived from fully specified intertemporal optimization problems with rational expectations. (2) The general equilibrium of the model must be fully specifted. (3) Both the qualitative and quantitative properties of the model should be studied. Lucas argued in 1980 , before work began on RBC models, that theoretical developments beginning with Hicks, Arrow and Debreu allowed modert economists to begin work which met the first two criteria. The dramatic fall in the price of capital (computers) has made it possible to meet the third criterion as well, allowing macroeconomists to explore their models in much greater depth (although this potential is not always realized). This article is concerned mostly with giving an outsider a feel for how the third requitement is met. It proceeds by describing the theory underlying a standard RBC model, explaining what constitutes an equilibrinm, and then delving into the mechanics of solving a specific model (Hansen's landmark indivisible labor model) using a specific technique. I conclude with two illustrations of how the basic methodology can be extended to study fiscal and monetary policy.

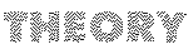

The typical RBC model is an ArrowDebreu type economy, specifically a onesector stochastic growth model. Many identical consumers who live forever maximize expected utility (derived from goods and leisure) subject to an intertemporal budget constraint. Competitive frrms purchase factors in competitive markets. Uncertainty comes from a stochastic shock to the economy's production technology.

For simplicity, suppose that consumers own capital directly and rent it to firms. Firms buy capital and labor services from consumers and use them to produce a single output which can be used as either consumption or investment. Output is the numeraire. The firms' technology is described by an aggregate con-

\footnotetext{
1 Outides would fodude, omong

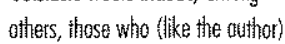
ware thetcoted where these models ware not in fowat and those who (tike the suthor) finished sthoo jefore these raotels hatd a large noviket shase.

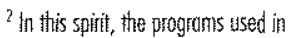
the orticle ure owotate on the FRE elactronic bultetin boud. For

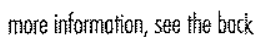
cover of this issute.
} 
stant-returns-to-scale production function which includes an exogenous aggregate technology shock, $A_{i}: A_{t} F\left(K_{t}, L_{t}\right)$, where $K_{t}$ and $L_{t}$ are the aggregate levels of capital and labor. ${ }^{3}$ The $A_{t}$ are usually taken to be serially correlated, but the exact specification can be postponed. These are simple competitive firms which will purchase labor and capital services at wage $W_{t}$ and rental price $R_{t}$ up to the point where their marginal products equal $W_{i}$ and $R_{i}$, respectively:

(1) $W_{t}=A_{i} F_{L}\left(K_{i}, L_{t}\right), \quad R_{t}=A_{t} F_{K}\left(K_{t}, L_{t}\right)$.

Let $\vec{l}$ be a consumer's time endowment, $l_{t}$ the amount of labor she supplies, $c_{i}$ her consumption, $k_{t}$ her holdings of capital and $i_{t}$ her rate of gross investment. (Upper case will be reserved for aggregate variables.) The consumer takes prices $W_{t}$ and $R_{t}$ as given. Given a starting value $k_{0}$, she chooses paths, that is, contingency plans, for $i_{t}$ and $l_{t}$ to maximize

$$
\mathrm{E}_{0}\left\{\sum_{t=0}^{\infty} \beta^{\mathrm{c}} u\left(c_{t}, \bar{l}-l_{t}\right)\right\}
$$

subject to a budget flow constraint

$$
c_{t}+i_{t} \leq R_{t} k_{t}+W_{t} l_{t}
$$

and a description of how capital accumulates and depreciates:

$$
k_{t}=(1-\delta) k_{t-1}+i_{t}, \quad 0 \leq \delta \leq 1
$$

For present purposes, it is more useful to shork $A_{i}$ was the diwiting force in most RBC models thence, 抽e "reat"). Both proponents and opponents recognized this os the Achithes heel of this hine of research. One response twos been the development of models in which fechnot. ogy is not the only source of utcesruitity (the last section contailas two exaringles s, though the criticism goes deaper then simply dianimg that there cofe other kinds of stocks (see Stadler, 1994, section W.A.).

${ }^{4}$ The exoct sequence of substitutions hese is lesigned to hanumet the model into the mold requiret: loter for a sperfic nutretercol solution mettod. For excmple, it tod d eusi Whe eliminoted from the problem using 3 , bet that wald be jaconwenient loter. which prescribe $i_{t}$ and $l_{t}$ as functions of current state variables, $k_{i}, K_{t}$ and $A_{t}$ :

$$
i_{t}=\dot{i}\left(k_{i}, K_{t}, A_{t}\right), \quad l_{t}=l\left(k_{t}, K_{t}, A_{t}\right) .
$$

These decision rules depend only on the state variables which fully describe the position of the economy at the beginning of $t$ and which, therefore, contain all of the information needed to decide optimal levels of $i_{t}$ and $l_{t}$. A great deal of information about how the economy works-about the structure of the model, in other words-will be embedded in these functions when we find them.

In addition to capital, there may be many financial assets with a net supply of zero, but, since consumers are identical and the economy is closed, these assets would be redundant. Nevertheless, the prices of these assets are determined by the model; once equilibrim quantities are known, they can simply be substituted into the Euler equation for each asset to determine its price.

Since consumers and firms are identical, this artificial economy is mathematically identical to a representative agent economy in which one price-taking consumer sells labor and capital services to a single price-taking firm. On the surface, finding an equilibrium appears to be a very daunting task. Even though we have reduced the number of consumers and firms to one each, we still have an infinite number of goods: consumption and leisure in various states of the world at dates from 0 to infinity. However, a great deal is known about the theory underlying this type of economy (Stokey, Lucas and Prescott, 1989), and this theory provides important tools that allow simulations to be constructed.

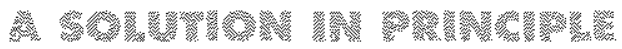

For the representative consumer, the state of this economy at the beginning of $t$ is summarized by the individual's capital stock $k_{i}$, the aggregate capital stock $K_{t}$ and the state of technology $A_{t}$. Thus, the maximum lifetime utility attainable by the consumer will be a function $V$ of $k_{t}, K_{t}$ and $A_{t} . V\left(k_{t}, K_{t}, A_{t}\right)$ is the value function for the consumer's utility maximization problem.

The core of the problem is to find $V$. To frame the solution in terms of decision rules start, substitute the budget constraint (2) into the consumer's utility function, then substitute marginal products for $W_{i}$ and $R_{f}$ as described by equation 1 . The latter substitution implicitly defines the consumer's rational expectations of factor prices in terms of present and future values of aggregate labor and capital. In other words, the consumer does not care about $K_{t}$ and $L_{t}$ per se; they merely contain the same information as $W_{t}$ and $R_{t}{ }^{6}$. We now have

$$
\begin{aligned}
& E_{0}\left\{\sum _ { i = 0 } ^ { \infty } \beta ^ { \imath } u \left(A_{\imath} F_{K}\left(K_{i}, L_{i}\right) k_{\imath}\right.\right. \\
& \left.\left.+A_{t} F_{l}\left(K_{t}, L_{l}\right) l_{t}-i_{n}, \bar{l}-l_{l}\right)\right\} \text {. }
\end{aligned}
$$

In period 0 , the consumer is choosing $i_{0}$ and $l_{0}$. Rewrite utility as 
(4)

$$
\begin{aligned}
& u\left(A_{0} F_{K}\left(K_{0}, L_{0}\right) k_{0}\right. \\
& \left.+A_{0} F_{L}\left(K_{0}, L_{0}\right) l_{0}-i_{0}, \overline{1}-l_{0}\right) \\
& +\beta \mathrm{E}_{1}\left\{\sum _ { i = 1 } ^ { \infty } \beta ^ { \mathrm { t } } u \left(A_{\mathrm{t}} F_{k}\left(K_{t}, L_{l}\right) k_{t}\right.\right. \\
& \left.\left.+A_{t} F_{K}\left(K_{l}, L_{i}\right) l_{i}-i_{t}, \bar{l}-l_{l}\right)\right\}
\end{aligned}
$$

Examination of the second term in 4 reveals an important feature of the optimization problem; apart from the values of state variables, the consumer will solve exactly the same problem in period 1 as in period 0 . For an optimal plan, this recursion is summarized in the Bellman equation for the consumer's problem at $t$ :

$$
\begin{aligned}
& V\left(k_{i}, K_{t}, A_{i}\right) \\
& \quad=\max _{i, t}\left\{u\left(\mathrm{i}_{t}, l_{t}, h_{t}, K_{t}, L_{t}, A_{t}\right)\right. \\
& \left.\quad+\beta \mathrm{EV}\left\{\left(k_{t+1}, K_{t+1}, A_{t+1}\right) \mid A_{t}\right\}\right\}
\end{aligned}
$$

The maximization on the right is subject to the constraint (3) that connects investment and capital. Embedded in 5 is Richard Bellman's deep insight that if you know the value of your problem next period for the various values of state variables, it is a relatively simple matter-a static maximization- to figure out the optimal action now.

There are four kinds of variables in 5 : individual decision variables $\left(i_{t}, l_{l}\right)$; an individual state variable $\left(\mathcal{K}_{i}\right)$; economy-wide state variables $\left(K_{t}, A_{t}\right)$; and an economy-wide variable. determined in $t(L)$. The state variables are determined at the start of $t$ or inherited from $t-1$. The contemporaneously determined econotny-wide variable $L_{i}$ appears because (for mathematical reasons evident below) we have substituted out $W_{t}$ and $R_{t}$. These market-clearing prices would otherwise summarize the information contained in $K_{x}$ and $L_{t}$ that is relevant to the consumer's decision. Our task is to find a recursive competitive equilibrium, that is, decision rules $i\left(k_{i}, K_{i}, A_{i}\right)$ and $l\left(k_{t}, K_{i}, A_{t}\right)$ for the household, functions $I\left(K_{i}, A_{t}\right)$ and $L\left(K_{t}, A_{t}\right)$ determining aggregate investment and labor, and a value function $V\left(k_{i}, K_{l}, A_{i}\right)$ such that

$$
\begin{aligned}
& V\left(k_{2}, K_{2}, A_{1}\right) \\
& =u\left(i\left(k_{i}, K_{l}, A_{z}\right), l\left(k_{t}, K_{t}, A_{t}\right), k_{v}\right. \text {, } \\
& \left.K_{h}, L\left(K_{e}, A_{t}\right), A_{t}\right) \\
& +\beta \mathrm{E}\left\{V\left(k_{\mathrm{t}+1}, K_{t+1}, A_{t+1}\right) \mid A_{\mathrm{t}}\right\}
\end{aligned}
$$

with

$$
\begin{aligned}
L\left(K_{i}, A_{i}\right) & =l\left(K_{t}, K_{t}, A_{t}\right) \\
\text { and } l\left(K_{1}, A_{i}\right) & =i\left(K_{v}, K_{i}, A_{i}\right)
\end{aligned}
$$

Condition 6 says that, given expectations L( $(\cdot)$, decision rules $i(\cdot)$ and $l(\cdot)$ are optimal for consumers. The equations in $\bar{l}$ say that expectations of aggregate labor supply and investment are consistent with individual decisions. Only a small number of examples can be solved analytically (for example, Long and Plosser, 1983), so we must now turn to the computer.

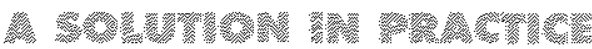

To compare the time-series behavior of the model's equilibrium with the time-series behavior of actual economies-1o evaluate its quantitative implications-requires that we simulate the model using specific functional forms and parameter values. The process of choosing parameter values, calibration, is deferred to the next section. The next few sections illustrate solution procedures by fully specifying, calibrating and solving Gary Hansen's (1985) indivisible labor model, an early landmark in the RBC literature. Hansen's relatively simple model provides a clear illustration, but should not be taken as the state of the art. The solution follows one of the popular linear-quadratic approximation methods.

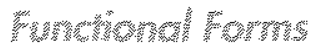

Subsequently, the production function is assumed to be Cobb-Douglas:

$$
A_{i} F\left(K_{l}, L_{l}\right)=e^{\lambda_{l}} K_{i}^{\theta} L_{l}^{L-\theta} .
$$

The technology shock $e^{\lambda_{i}}$ is driven by an AR(1) process:

$$
\lambda_{i}=\gamma \lambda_{\mathrm{t} ; 1}+\varepsilon_{\mathrm{s}}, \quad|\gamma|<1,
$$

where the $\varepsilon_{i}$ are independent and identically

\footnotetext{
Hagsen and Prescotit (1995) would

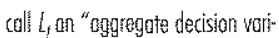
able." Other solutina methots would solve for pricing rutes ttent sperify $W_{i}$ and $R_{i}$ as functions of state vatiobles ratier that for on "oggregnte decision wiet" for $L_{f}$. In either cose, the tunctions cophuse the substronce of the assumpitian of retiond expectotitins.

${ }^{6}$ Toytor and ullitig (1990) corpgete number of alaptoractess fo solving stockinstic grewtil models. Other papers in the same issue of the Jound of Business and Economic Statisfics provide short descriptions of the various solution methods.
} 
distributed normal random variables that are independent of all $t-1$ variables.' It is easier to work with $\lambda_{t}$ rather than $A_{t}$ as a state variable from this point forward.

The utility function is specified in a somewhat unusual way that incorporates indivisibility of labor inputs, the contribution of Hansen's paper,

$$
U\left(c_{t}, \tilde{l}-l_{i}\right)=\log c_{t}+B(\bar{l}-1)
$$

where $B$ is a constant. The Bellman equation 5 becomes

$$
\begin{aligned}
V\left(k_{t},\right. & \left.K_{t}, \lambda_{t}\right) \\
= & \max _{l, i_{t}}\left\{\operatorname { l o g } \left(e^{\lambda_{1}} F_{K}\left(K_{t}, L_{t}\right) k_{t}\right.\right. \\
& \left.+e^{\lambda_{2}} F_{L}\left(K_{t}, L_{t}\right) I_{t}-i_{t}\right) \\
& +B\left(\bar{l}-l_{t}\right) \\
& \left.+\beta \mathrm{E}\left\{V\left(k_{t+1}, K_{i+1}, \lambda_{t+1}\right) \mid \lambda_{t}\right\}\right\}
\end{aligned}
$$

Hansen showed that using a representative consumer with this utility function produces the same competitive allocations as individual consumers described in the following way. Each consumer works either $l_{0}$ hours or not at all, but gets paid in either case. The probability of working, chosen by the consumer, is $\alpha_{\mathrm{r}}$. Labor supply is determined indirectly by choosing $\alpha_{t}$ rather than directly by choosing $l_{r}$. Total labor time in the economy is thus $I_{2}=\alpha_{t} I_{0}$. If the utility function of individual consumers is

$$
U\left(c_{\mathrm{z}} \alpha_{i}\right)=\log c_{t}+A \alpha_{1} \log \left(\bar{l}-t_{0}\right)
$$

with $A>0$, then the reptesentative consumer will have utility 9. By making these modifications, Hansen hoped to improve on the rather poor performance of the basic model

This specticcition diffests slightly from Hurstent's, 败ich assumes that the technougy is $\lambda_{F} F\left(K_{r}, L_{f}\right.$, , with $\varepsilon_{F}$ log-normaly ly sistituted theice of

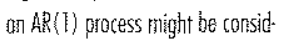
efed part as calibration sictce a spec-

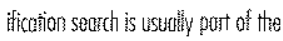

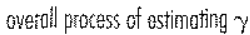

${ }^{3}$ The mettud doretibed the and in

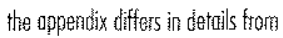
Hensen ond Prescoti's angrithen. the early RBC literature, would work like this: Since agents are identical in this model, a Pareto optimum can be found by maximizing utility (9) subject to society's production possibilities, ignoring market structure. Production possibilities are described by the production function, the process generating technology shocks, and the capital accumulation equation. This is a much simpler problem. Since the model has no distortions, the Second Welfare Theorem applies: The Pareto optimal allocation can be supported as a competitive equilibrium. Thus, the solution to the social planner's problem replicates the outcomes of a decentralized competitive system.

Rather than taking the shortcut of solving the social planner's problem, this section follows the more general method described in Hansen and Prescott (1995) that also applies to models with distortions. ${ }^{8}$ Two such models are briefly described in the section titled "Extending the Basic Model."

There are two keys to finding the value function $V$ using functional equation 5 or $5^{\prime}$. The first is approximation, described shortly. The second is the Contraction Mapping Theorem, a fixed point theorem, which guarantees that for certain problems the following steps will converge to the value function $V$. The theorem does not actually apply to many RBC models, so there is no guarantee in general, but this approach usually converges anyway, finding the correct value function.

1. Choose an arbitrary function $V^{r 0}\left(k_{i \neq 1}, K_{i+1}, \lambda_{i+1}\right)$

2. The problem on the right-hand side of 5 is now a static optimization. Solve it to get decision rules $i_{t}=i\left(k_{\mathrm{r}}, K_{\mathrm{t}}, \lambda_{\mathrm{t}}\right)$ and $I_{l}=l\left(k_{t}, K_{t}, \lambda_{t}\right)$. Substitute these into the right-hand side to produce a new funcLion, $V^{\mathrm{l}}\left(k_{t}, k_{1}, \lambda_{t}\right)$.

3. Replace $V^{3}$ on the right-hand side of 5 with $V^{1}\left(k_{t+1}, K_{t+1}, \lambda_{t+1}\right)$. Return to step two unless $V^{\prime}$ and $V^{i+1}$ are almost identical.

Unfortunately, in general, step 2 will not produce a function that can be written down in any compact way, particularly given the presence of the expectation in the middle of the right-hand side of 5 . This problem is addressed in Hansen and Prescott's method by solving a cquadratic approximation of the 
model, rather than the full model. Variations on the linear-quadratic approximation have been the most common method of solving dymanic general equilibrum models, starting with Kydland and Prescott (1982).

For simulation purposes, the model is approximated by a Taylor series expansion of the utitity function (as it appears in 4 after all the substitutions) around the steady-state equilibrium values $(\bar{K}, \bar{L}, \bar{\lambda})$ that would occur if we set all the shocks to zero. In some models; the zero-shock equilibrium is not a steady state. In these cases, a simple change of variables usually produces the required steady state. If, for example, the population were assumed to be growing, the model would be formulated in per capita terms. For Hansen's model, $\left(5^{\prime}\right)$ becomes

$$
\begin{aligned}
& V\left(k_{r}, K_{r}, \lambda_{i}\right) \\
& =\max _{l_{i}, i_{i}}\left\{Z_{\mathrm{t}}^{\prime} Q Z_{\mathrm{t}}\right. \\
& +\beta E\left\{V\left(k_{t+1}, K_{1+1}, \lambda_{t+1}\right)\left[\lambda_{t}\right]\right\}
\end{aligned}
$$

where $\left.Z_{t}=11 \lambda_{t} k_{t} K_{t} i_{t} l_{t} I_{i} L_{t}\right]^{\prime}$. Including $I$ as a state variable allows the quadratic approximation to be written as a single quaGratic form (see the appendix).

The beauty of the quadratic approximation is threefold. First, one can guess (correctly) that the value function is quadratic. Second, it does not depend on the distribution of $\varepsilon_{t}$ except for a constant that involves the covariance matrix of $\varepsilon_{t}$. Third, this constant is not essential for our analysis because it does not involve any of the state variables. Because the constant is not essential, we can ignore it and the expectation along with it. For details, see Sargent (1987, section 1.8), but it is not difficult to see that the iterations described above will always produce a quadratic if $V^{\circ}$ is quadratic.

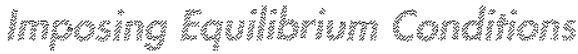

Most of the pieces of a solution method have already been described, but there is one missing, namely, how to handle $L_{t}$. This is neither a state variable nor a decision variable of any agent. It is an aggregate outcome of households' decisions. The aggregation happens to be trivial here because there is only one household. But the distnction between l, and $L_{1}$ must be maintained because the household must behave as if it takes prices $(W$, and $R$ ) as given, and these would be functions of $L_{l}$, not $l_{i}$, if we had more than one consumer.

So how should $L_{t}$ be handled? (Though it does not appear in the model, we also need to wony about $I_{4}$ for reasons that will becone clear momentarily.) The model assumes that households have rational expectations about $L_{\mathrm{q}}$ and $I_{t}$, so they recognize that equilibrium values of these variables will satisfy the first-order conditions. In maximizing the right-hand side of $5^{\prime \prime}$ at each iteration, the frrst-order conditions define a linear relationship among choice variables $l_{1}$ and $i_{f}$, aggregates $L_{1}$ and $l_{f}$, and state variables:

$$
\begin{aligned}
& 0=u_{0}+u_{1 !} l_{t}+u_{2 i} \hat{i}_{t}+u_{31} L_{t} \\
& +u_{4 l} I_{t}+u_{51} k_{t}+u_{6 !} K_{t}+u_{7 !} \lambda_{t} \\
& 0=u_{0 i}+u_{3 j} L_{i}+u_{2 i} i_{1}+u_{3 i} L_{j} \\
& +u_{+1} I_{1}+u_{5 i} k_{r}+u_{6 i} K_{t}+u_{i i} \lambda_{t} .
\end{aligned}
$$

The firstorder conditions can be solved for $l_{t}$ and $i_{i}$ to get household decision rules speciffed in terms of state variables, as well as $L_{i}$ and $I_{t}$. However, if $L_{t}$ is substituted for $l_{t}$ and $i_{t}$ for $i_{t}$ in the first-order conditions (thus imposing 7 ), the equations can be solved for $L_{t}$ and $I_{t}$ as functions of state variables. These solutions can be interpreted as households' conditional expectations of aggregate labor supply and investment, given the current values of state variables. Hansen and Prescott call these "aggregate decision rules." The solutions for aggregate labor supply and investment replace $L_{t}$ and $I_{t}$ in the household decision rules which then become functions of state variables alone." This procedure ensures that condition 7 for a recursive competitive equilibrium is satisfied at every iteration.

When the value function approximations converge, we have found a value function, decision rules for $l_{t}$ and $i_{t}$, and aggregate labor supply and investment functions that satisfy equations 6 and 7 by construction. The Contraction Mapping Theorem does not apply to this particular dynamic programming problem, but the algorithm does find the value function

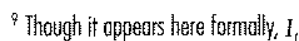
drops out of household decisiont rules for this motel, 期时 is $y_{4 !}=v_{4 i}=0$.
} 


\begin{tabular}{|c|c|c|c|c|}
\hline \multicolumn{5}{|c|}{$\begin{array}{l}\text { Percentage Standard Deviations and } \\
\text { Correlations with Output }\end{array}$} \\
\hline & \multicolumn{2}{|c|}{ Unitedstotes } & \multicolumn{2}{|c|}{ Model } \\
\hline & SD, & Corr & S.0. & Corr. \\
\hline Output & 176 & 100 & 176 & 100 \\
\hline Consumptiren & 129 & 0.85 & 051 & 086 \\
\hline Gevestnent: & 860 & 002 & 575 & 099 \\
\hline copint) & 063 & 004 & 048 & 006 \\
\hline Vlours? & 166 & 076 & 134 & 0,98 \\
\hline Protingrivy & 118 & 0.42 & 05 & 007 \\
\hline
\end{tabular}

if given an appropriate $V^{0}$. The results are, of course, subject to the caveat that if shocks take the economy too far from the steady state, the quadratic approximation may not be accurate.

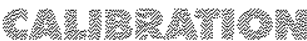

There are six unknown parameters in the description of Hansen's model, $\theta, \delta, \beta, B$, $\gamma$ and the variance of $\varepsilon$. Hansen chose values as follows. Given Cobb-Douglas technology, $\theta$ is capital's share of output. He used an esti mate of $\theta=0.36$ based on time series for the U.S. economy, A choice of $\delta=0.025$ (corresponding to an annual depreciation rate of 10 percent) was chosen as "a good compromise given that different types of capital depreciate at different rates." A steady-state annual riskless real interest rate of 4 percent would be implied by $\beta=0.99$. Hansen chose $B=2.85$, which corresponds to an apparently arbitrary value of $A=2$ in 10 , combined with $l_{0}=0.53$ The 0.53 value equated steady state hours in Hansen's divisible and indivisible labor models.

The standard deviation of $\varepsilon$ was chosen so that, for the artificial economy with indivisible labor, the standard deviation of detrended output would be about the same as that of detrended GNP for the U.S. economy. A value $\sigma_{\varepsilon}=0.00717$ meets this criterion. ${ }^{19}$ A value of $\gamma=0.95$ was the first-order antocorrelation coefficient of the Solow residuals for the U.S. economy.
Calibration strategies are often much more complex than this, and the justifications more elaborate, but they always have the same simple purpose, to select a plausible parameter point at which to study the behavior of the model. Kydland and Prescott (1994) detail calibration strategies and their own philosophy of calibration. Researchers often conduct informal sensitivity analyses, varying the parameters whose values are most uncertain. The most common such exercise seems to be to vary the risk aversion parameter in models in which utility is of the constant relative risk aversion form.

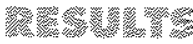

Once the value function is found and agents' decision rules are known, it is relatively simple to simulate the model. The equations of motion for $\lambda_{t}$ and $K_{l}$ along with the aggregate decision rule for $l_{\text {, }}$ are a system of three linear difference equations in three unknowns that can easily be simulated. (Recal that $K_{\mathrm{t}}=k_{\mathrm{f}}$ in equilibrum.) Starting values are chosen for the state variables and innovations $\varepsilon_{\text {f }}$ are drawn randomly.

The real and artificial data are fllered by taking logarithms and detrending with the HodrickmPrescott filter, There are two reasons for filtering. First, the model is intended to explain phenomena at business cycle frequencies, and the Hodrick-Prescott filter highlights those frequencies. The models are not intended to match long-run growth lacts, so it would be unfair to compare low-frequency movements in the data with those from the model. A filter that removes low-frequency movements in the data and model output allows the model to be compared to phenomena in the data it was designed to explain.

Second, many macroeconomic time series may not be stationary. If this is true, their second moments do not exist. Though it would still be possible to generate sample second moments, there would be no reason to think that another set of observations on the same economy would produce sample second moments similar to the first set. Thus, there would be no point in trying to produce models that matched a particular set 
of sample second moments. Filtering that induces stationarity removes this problem in the sense that samples drawn from the same data-generating process would be expected to produce similar sample second moments.

There are other ways to filter the data, by taking first differences, for example. While the Hodrick-Prescott filter is somewhat controversial (Cogley and Nason, 1995; King and Rebelo, 1993), proponents argue that it does a good job of emphasizing the movements in the data that most macroeconomists would call business cycle movements. For example, Kydland and Prescott (1990) say "...the implied trend path for the logarithm of real GNP is close to the one that students of business cycles and growth would draw through a time plot of this series." Cogley and Nason argue, on the other hand, that if the data are an integrated process, "the filter can generate business cycle periodiciey and co-movement even if none are present in the original data. In this respect, applying the HP filter to an integrated process is similar to detrending a random walk."

The results in Table 1 summarize 500 simulations of 115 periods each. The statistics are calculated from natural logarithms of each series detrended using the Hodrick-Prescott filter with a parameter of 1600 . Each simulation chooses $\lambda_{0}$ from the unconditional distribution of $\lambda_{t}$. This is more difficult for $K_{0}$, so I simulate the model for 100 periods, starting $K$ at its steady-state value. The value after 100 periods is used as $K_{0}$ for the simulations reported in Table $1 .^{12}$ In other words, I simulate the model for 215 periods and throw away the first 100 in order to get a representative distribution of starting capital stocks. This procedure allows the statistics reported in the table to be interpreted as averages across 500 identical artificial economies with independent realizations of the technology shocks.

Evaluation of RBC models' output has usually been informal. Hansen, for example, was interested in how well this indivisible labor model performed relative to a more standard divisible labor model (with utility given by $\log c_{t}-A \log l_{t}$ ). He noted that the standard deviation of hours relative to that of productivity in the divisible labor model was only about 1 compared to $1.34 / 0.51=2.6$ for the indivisible labor model and 1.4 for the U.S. economy. He argued that the indivisible labor model showed promise because standard models chronically produced ratios that were too small. Since the real world is not characterized by fully indivisible labor, he argued, it was good that the ratio for the U.S. economy lay between the two models' predictions.

A few additional tools have been used to evaluate model output. A fairly common approach is to compare impulse response functions from the model with those from a vector-autoregression on the data. Watson (1993) has proposed a procedure for evaluating the fit of a calibrated model. A variety of new approaches is discussed in Pagan (1994), which is a thought-provoking overview of calibration exercises.

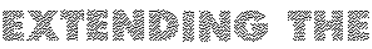

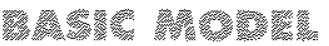

The solution technique described above is more powerful than needed to solve Hansen's model, but makes it possible to outline how more sophisticated models can be handled. I've chosen two examples from areas in which extensive contributions have been made. These particular papers fit easily into the framework developed above.

\section{Fiscal Policy}

One obvious road to follow in generalizing the basic RBC model is to add fiscal policy to the model. Though obvious, this was not initially an easy road because a minimally realistic model requires distorting taxes. The first generation of solution methods that relied on solving the social planner's problem are not appropriate for models in which the Second Welfare Theorem is not true.

A recent contribution in this area is McGrattan (1994a, 1994b), which developed a model in which agents face stochastic tax rates on both labor and capital income. McGrattan (1994b) modified the indivisible labor model as follows. The government uses tax revenue to fund government purchases and lump-sum transfers. Thus, the consumer's budget constraint (2) is replaced by

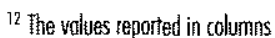
three ond four of Thate 1 differ wey slightly from those repoted by Hansen. Sompling vasiotion and a stightly difterent process generating $\lambda$ probaty occount for the uifferences.
} 


$$
\begin{aligned}
c_{t}+i_{t} \leq & \left(1-\tau_{i}\right) R_{i} k_{t} \\
& +\delta \tau_{t} k_{t}+\left(1-\phi_{t}\right) W_{t} l_{t}+\xi_{t},
\end{aligned}
$$

where the capital tax allows a depreciation deduction and $\xi_{t}$ is the lump-sum transfer. The tax rates, $\tau_{i}$ and $\phi_{i}$, and government purchases, $g$, are exogenous state variables (like the technology shock $\lambda_{t}$ ). The size of the transfer is determined by the government budget constraint which imposes period-byperiod budget balance:

$$
\xi_{t}=\tau_{t}\left(R_{t}-\delta\right) K_{t}+\phi_{t} W_{t} L_{t}-G_{t} .
$$

The representative agent must form expectations about $\xi_{i}$ assuming that her decisions have no influence over govertment revenue. Thus, $K_{t}$ and $L_{t}$ rather than $k_{t}$ and $l_{t}$ appear in the government budget constraint. In this model, there are four exogenous state variables, $\lambda_{t}, \tau_{t}, \phi_{t}$ and $G_{t}$. McGrattan calibrated the stochastic processes for these variables by estimating a first-order autoregression for each. She argues that her results indicate the addition of these fiscal shocks to the basic indivisible labor model brings it into "much better agreement with the data."

To solve the model using the procedure outlined above, substitute the new budget constraint into the utility function, as before. ${ }^{\text {.3 }}$ Then substitute the right-hand side of the government budget constraint for $\xi_{\mathrm{t}}$. Add the assumed stochastic processes for tax rates and government purchases to the list of equations of motion (the matrix $A$ in the language of the appendix).

\section{Monsy}

Cooley and Hansen (1989) studied an RBC model with a cash-in-advance constraint. In the simpler version of their model, the money supply $M_{t}$ grows at a constant rate, $g$ :

$$
M_{t}=(1+g) M_{t-1} .
$$

Households' consumption decisions must satisfy the cash-in-advance constraint,

$$
P_{t} c_{t} \leq m_{t-1}+g M_{t-1},
$$

${ }^{13}$ MeGrottan actually used a neithod described in McGrattan (1994) $)$. which says that the nominal value of consumption purchases, $P, c_{t}$, must not exceed money balances carried over from last period, $m_{t+1}$, plus the lump-sum transfer of seigniorage revenue, $g M_{t-1}$.

The household budget constraint is

$$
\begin{aligned}
P_{t} c_{t}+P_{t} i_{t}+m_{t}= & P_{t} W_{t} l_{t}+P_{t} R_{t} k_{t} \\
& +m_{t-1}+g M_{t-1} .
\end{aligned}
$$

The last term on the left represents money balances carried into $t+1$.

Because positive money growth results in inflation, it is necessary in this model to make a change of variables for the zeroshock path to be stationary. (Recall that we need a steady state around which to form a quadratic approximation.) There is a steady state when the model is written in terms of $\hat{m}_{t}=m_{t} / M_{i}$ and $\hat{P}_{t}=P_{t} / M_{i}$. The two constraints (transformed by the change of variables) are used to eliminate $c_{t}$ and $l_{t}$ from the consumer's utility function, leaving an optimization over $m_{l}$ (money holdings carried into $t+1)$ and $i$.

The money supply $M_{t}$ is an exogenous state variable, and is added to the list of equations of motion. The endogenous state variables are $k_{t}, K_{t}$ and $m_{t-1}$. An equation of motion that says that this period's purchases of money become next period's money state variable is added to the list for endogenous state variables (the $B$ matrix in the notation of the appendix).

The aggregates that must be determined are an investment function $I\left(\lambda_{\mathrm{t}}, M_{\mathrm{t}}, K_{\mathrm{p}}\right)$ and an aggregate price function $P\left(\lambda_{t^{2}}, M_{t^{2}} K\right)$. Since $M_{t}$ is exogenous, there is no aggregate that corresponds directly with the decision variable $m_{t}$. The aggregate price level $P_{t}$ serves this role instead: At each teration, $I\left(\lambda_{t}, M_{t}, K_{t}\right)$ and $P\left(\lambda_{t}, M_{t}, K_{t}\right)$ are chosen by setting $i_{t}=I_{t}$ and $\tilde{m}_{t}=1$ (that is, $m_{t}=M$ ) in the first-order conditions and solving for $I_{t}$ and $P_{t}$ as functions of state variables. (For Hansen's model, by contrast, we set $i_{t}=I_{t}$ and $l_{t}=L_{t}$ in the firstorder conditions, then solved for $I_{t}$ and $L_{t}$ ) Details on how to handle this slight variation can be found in Cooley and Hansen (1989).

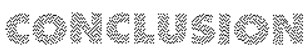

RBC methods have found application in a wide spectrum of questions in business cycles, monetary economics, open economy macroeconomics and finance. The linear- 
quadratic approach described in this paper is a popular tool that can be applied to a broad cross-section of the questions posed in this literature. More generally, careful study of a specific method illustrates how equilibrium conditions must be tied to optimization to find an equilibrium numerically.

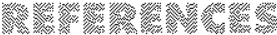

Blanchod, Olivier Jean, and Stanley Fischer. Lectures on Marroeconomics, The MIT Prass, 1989.

Cogley, Timothy, and James M. Nason. "Effects of the Hodrick-Prescott Fitter on Trend and Difference Stationary Time Series: Implications for Business Cycle Research," Jound of Econonic Dynamics and Control (Jonewry/Febuary 1995)

Cooley, Thomos F, and Gory D. Hansen. "Tha Infiation Tax in o Red Business Cycle Model," The American Fonomic Review (September 1989).

Mansen, Gory D. "Indwisible tubor and the Business Cyde," Journd of Monetary Econonios (November 1985).

and Edword C. Prescott. "Recussive Mettods for Compiting Equilitio of Busittess Cyde Models," thaper 2 in Thonas F. Cooley, ed. Frontiers of Business Cyde Reseorch. Princeton University Press, 1995.

King, Robert G., and Sergio T. Rebela. "Low Frequency Fittering and Red Business Cycles," Jound of Economic Dynomics and Control (januory/March 1993).

Kydiand, Finn E., and Edward C. Prescott. "The Computotand

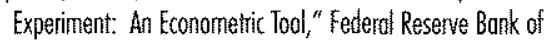
Minnerpolis Staff Report 178 (August 1994).

ond . Business Cydes: Real Facts and o Monetary Ayth," Federd Reserve Bonk of Minneapolis Review (sping 1990).

Long, John B., and Charles I. Plosser. "Real Business Cycles," Journal of Political Economy (Februan 1983).
Fluctuotions" and "Fonometrico (November to Build and Aggregote

Lucas, Robert E. "Methots and Problems in Business Cycle Theory," Jound of Money (redit ond Banking (November 1980, pot 2).

"Understanding Business Cycles," Comegie-Rochester Series on Public Policy (1977).

McCallum, Benneft T. "Real Business Cycle Models" in Robert I. Barro, ed. Madem Business Cycle Theory. Hofvatd University Press, 1989.

McGrattan, Ellen R. "A Progress Report on Business Cycle Models," Federat Reserve Bonk of hintecenolis Quorterly Review (fall 1994). "The Macroeconomic Effects of Distortionary Taxation," Jound of Monetory Economic (June 1994).

"A Note on Computing Competitive Equilibria in Linear Hodels," Jound of Economic Dynomics and Control (Jonudy 1994).

Pagan, Adran. "Colibation and Ecomemetic Researct: An Overiew," Jound of Applied Econometrics (Decentar 1994, supplement).

Plasser, Chates I. "finderstanding Real Business Cycles," Jound of Economic Perspectives (summer 1989).

Sargent, Thomas !. Oynomic Macroeconomic Theon. Horvard Univessity Press, 1987

Stadler, George W. "Rent Business Cyctes," Jound of Economic Literoture (December 1994).

Stokey, Nency L., Robert E. Lucos and todward C. Prescott. Rearsive Methods in Economic Omonics. Horvord University Press, 1989.

Taylor, John B., and Handd Uhlig. "Solving Nonlineor Stachastic Growth Models: A Comporison of Aternative Solution Methods," Jound of Business and Economic Statistics (lanuary 1990).

Warson, Mork W. "Meosures of Fit for Callobrated Models," Jound of Politicol Economy (Decembar 1993). 


\section{FINDING THE VALUE FUNCTION}

\section{Motentions}

Let $\rho(x)$ be the number of rows in the vector $x$. Let $z$ be the vector of exogenous state variables, $s$ and $S$ the vectors of individual and aggregate endogenous state variables, $d$ the vector of decision variables, and $D$ the vector of "aggregate decision variables." For reasons of convenience, the first element of $z$ is always 1. Let

$$
\begin{aligned}
X & =\left[\begin{array}{c}
z \\
s \\
s
\end{array}\right] \\
\text { and } \quad z & =\left[\begin{array}{l}
X \\
d \\
\mathrm{D}
\end{array}\right]
\end{aligned}
$$

Using $\sim$ to denote next-period values, the constraints are

$$
\begin{aligned}
& \bar{z}=A z+\varepsilon=\left[\begin{array}{lllll}
A & 0 & 0 & 0 & 0
\end{array}\right]\left[\begin{array}{l}
z \\
s \\
s \\
d \\
D
\end{array}\right]+\varepsilon \\
& \tilde{s}=B Z=\left[\begin{array}{lllll}
B_{1} & B_{2} & B_{3} & B_{4} & B_{5}
\end{array}\right]\left[\begin{array}{l}
z \\
z \\
s \\
d \\
D
\end{array}\right] \\
& \tilde{S}=\left[\begin{array}{lllll}
B_{1} & B_{2} & B_{3} & B_{4} & B_{5}
\end{array}\right]\left[\begin{array}{l}
z \\
s \\
s \\
D \\
D
\end{array}\right] \\
& =\left[\begin{array}{llllll}
B_{1} & 0 & B_{2}+B_{3} & 0 & B_{4}+B_{5}
\end{array}\right]\left[\begin{array}{l}
z \\
z \\
s \\
d \\
D
\end{array}\right]
\end{aligned}
$$

or, combining all three,

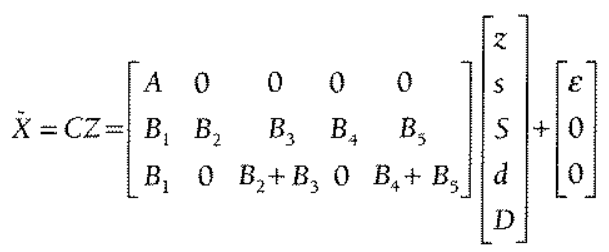

The matrix $C$ is $\rho(X) \times \rho(Z)$.

For Hansen's model,

$$
\begin{aligned}
& Z_{t}=\left[\begin{array}{llllllll}
l & \lambda_{t} & k_{i} & K_{t} & i_{t} & l_{t} & I_{t} & L_{t}
\end{array}\right]^{\prime} \text {, } \\
& A=\left[\begin{array}{ll}
1 & 0 \\
0 & \gamma
\end{array}\right] \text {, } \\
& B=\left[\begin{array}{llllllll}
0 & 0 & (1-\delta) & 0 & 1 & 0 & 0 & 0
\end{array}\right]
\end{aligned}
$$

\section{The Gererd Form of the problam}

Using the notation in Hansen and Prescott (1995), the problem we wish to solve in order to find an equilibrium is

$$
\begin{array}{cc}
V(X)=\max _{d} r(Z)+\beta E\{V(\bar{X}) \mid z\} \\
\text { subject to } \bar{X}=C Z+\left[\begin{array}{l}
\varepsilon \\
0 \\
0
\end{array}\right] \\
\text { with } \quad D=D(z, S)
\end{array}
$$

All nonlinear constraints have been. substituted into the return function $r$. As mentioned above, the $D=D(z, S)$ equation summarizes agents' rational expectations about aggregate values of their own decision variables, for example, labor supply. Since it does not involve the choice variables $d$, it is not really a constraint, but will be used to derive decision rules that depend only on $X$ rather than both $X$ and $D$. This is why the problem specifies "with" rather than "subject to."

\section{Srecty-stete solution}

The return function will be approximated around a steady-state solution to the model when $\varepsilon=0$. The steady-state solution solves 
the following set of $\rho(Z)$ equations in elements of $Z$ :

$$
\begin{aligned}
& X=C Z \text { (excluding the s rows) } \\
& 0=r_{d}(Z)+\beta r_{s}(Z)\left[1-\beta B_{s}\right]^{-1} B_{d} \\
& d=D \\
& s=s .
\end{aligned}
$$

The first vector equation contains $\rho(z)+\rho(S)$ scalar equations.' The second vector equation contains $\rho(d)$ scalar equations that are the first-order conditions for $d$. They take into account the recursive nature of $\mathrm{AI}$, that is, the fact that $d$ affects every future period by changing $s$. $B_{i}$ is the derivative of $B Z$ with respect to s, that is, the $\rho(s)$ columns of $B$ that correspond to the $s$ elements of $Z$ (the $\rho(z)+1$ through $\rho(z)+\rho(s)$ elements). Similarly, $B_{d}$ consists of the $\rho(d)$ columns of $B$ that correspond to the $d$ positions in $Z$ (the $\rho(X)+1$ through $\rho(X)+\rho(d)$ elements).

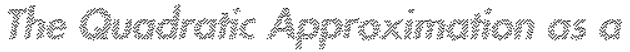 cuculyration}

Let $x$ be a $k$ row vector and let $\Psi$ be a $(k+1) \times(k+1)$ matrix. Partition $\Psi$ so that $\Psi_{11}$ is a scalar. Then

$$
\begin{aligned}
{\left[\begin{array}{l}
1 \\
x
\end{array}\right]\left[\begin{array}{ll}
\Psi_{11}^{\prime} & \Psi_{12}^{\prime} \\
\Psi_{21} & \Psi_{22}
\end{array}\right]\left[\begin{array}{l}
1 \\
x
\end{array}\right]=} & \Psi_{11}+\left(\Psi_{21}^{\prime}+\Psi_{12}\right) x \\
& +x \Psi_{22} x .
\end{aligned}
$$

Thus, any quadratic function from $\mathbf{R}^{k}$ into $\mathbf{R}$ of a vector $x$ can be written as a single quadratic form in $\left[1 x^{\prime} \mid\right.$ by collecting the constant terms in $\Psi_{11}$, the linear terms in $\left(\Psi_{21}^{\prime}+\Psi_{12}\right) x$, and the squared terms in $x^{\prime} \Psi_{22} x$.

The quadratic approximation to the return function is subsequently written in this way. Denote the quadratic approximation to $r(Z)$ by $Z^{\prime} Q Z$. The matrix $Q$ involves derivatives that can be calculated either analytically or numerically.

\section{Wubsthuting Out Constrain is and

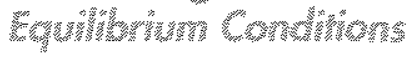

The remainder of this appendix describes the process of finding a sequence of approximations to the value function that converges to the actual value function for the linear- quadratic problem. The value function for this kind of problem is known to be quadratic. The first function in the sequence can be any quadratic function, but convergence is sometimes sensitive to the choice. Hansen and Prescott recommend $V^{(0)}=\eta I$, where $\eta$ is a small negative number.

If $V^{(n)}$ is the $\rho(X) \times \rho(X)$ matrix of the $n^{\text {th }}$ quadratic value function approximation, the $(n+1)^{\text {st }}$ approximation is given by

$$
\begin{gathered}
\max _{d} z^{\prime} Q Z+\beta \bar{X}^{\prime} V^{(n)} \bar{X} \\
\text { subject to } \bar{X}=C Z \\
\text { with } D=G X .
\end{gathered}
$$

The equation $D=G X$ summarizes the "aggregate decision rules" implied by $V^{(n)}$ (the derivation of these is described below). As explained above, this equation is not a constraint.

First eliminate the equations of motion for state variables to get an equivalent problem

$$
\max _{d} Z^{\prime} Q Z+\beta Z^{\prime} C^{\prime} V^{(n)} C Z \text { with } D=G X
$$

or

$$
\max _{d} Z^{\prime} R Z \text { with } D=G X
$$

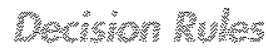

The first-order conditions for this problem are the second-to-last $\rho(d)$ rows (the $\rho(X)+1$ through $\rho(X)+\rho(d)$ rows) of

$$
0=\left(R+R^{\prime}\right) Z
$$

Write these $\rho(d)$ equations as

$$
0=U Z
$$

where $U$ is $\rho(d) \times \rho(Z)$.

Partition $U$ to conform with the components of $Z$ :

$$
0=\left[\begin{array}{lllll}
U_{1} & U_{2} & U_{3} & U_{4} & U_{\mathrm{s}}
\end{array}\right]\left[\begin{array}{c}
z \\
s \\
s \\
d \\
D
\end{array}\right] .
$$

Solving for $d$ yields ${ }^{2}$

$$
d=-U_{4}^{-1}\left(U_{1} z+U_{2} s+U_{3} s+U_{5} D\right) \text {. }
$$

The aggregate decision rules are obtained

\footnotetext{
Numerical metethos for solvang these entations asually teratire wopping the exultion thot

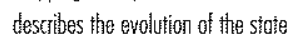
wainale 1. Most econonasts towe

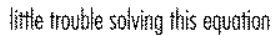
atulytically, howewe.

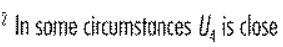
to siagular, which leads to corver gence problems. An taterntitive is

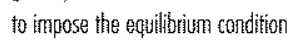
$D=d$ thefores solving for $d$, which instend requines $\left\{U_{i}+U_{5}, \cdots !\right.$. One coweat is needed, howewer. This

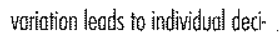
sion fules which thowe the weom weights on d and 0 , hough 菲e sum of the wenghts is cortect (50

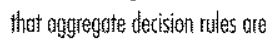
correct). If, for same season, indir viduol decision ratos pre needed, fine correct weights con be found by thoosticg them 50 that the firstander conditions used ir finding steody stote are satisfied with $D$ ot its equiliriuma rolues but with $d * 0$.
} 
by setting $d=D$ and $s=S$ in the first-order conditions. This leads to

$$
\begin{aligned}
D & =-\left(U_{4}+U_{5}\right)^{-1}\left[\begin{array}{lll}
U_{1} & 0 & \left(U_{2}+U_{3}\right)
\end{array}\right]\left[\begin{array}{l}
z \\
s \\
s
\end{array}\right] \\
& =G X .
\end{aligned}
$$

Substituting this into the previous equation gives individual decision rules that are functions of state variables only:

$$
\begin{aligned}
d & =-U_{+}^{-1}\left(U_{1} z+U_{2} s+U_{3} S+U_{5} G X\right) \\
& =-U_{4}^{-y}\left(\left[\begin{array}{lll}
U_{3} & U_{2} & U_{3}
\end{array}\right]+U_{5} G\right) X \\
& =H X .
\end{aligned}
$$

Substitute

$$
\begin{aligned}
{\left[\begin{array}{l}
d \\
D
\end{array}\right] } & =\left[\begin{array}{l}
H \\
G
\end{array}\right] X \\
& =J X
\end{aligned}
$$

into the objective function as follows to obtain the new value function:

$$
\begin{aligned}
& Z^{\prime} R Z=\left[\begin{array}{c}
X \\
J X
\end{array}\right]^{\prime} R\left[\begin{array}{c}
X \\
J X
\end{array}\right] \\
& =\left[\begin{array}{ll}
X^{\prime} & X^{\prime} J^{\prime}
\end{array}\right] R\left[\begin{array}{c}
X \\
J X
\end{array}\right] \\
& =\left[\begin{array}{ll}
X^{\prime} & X^{\prime} J^{\prime}
\end{array}\right]\left[\begin{array}{ll}
R_{11} & R_{12} \\
R_{21} & R_{22}
\end{array}\right]\left[\begin{array}{c}
X \\
J X
\end{array}\right] \\
& =\left[X^{\prime} R_{11}+X^{\prime} J^{\prime} R_{21} \quad X^{\prime} R_{12}+X^{\prime} J^{\prime} R_{22}\right]\left[\begin{array}{c}
X \\
J X
\end{array}\right] \\
& =X^{\prime} R_{11} X+X^{\prime} J^{\prime} R_{21} X+X^{\prime} R_{12} J X+X^{\prime} J^{\prime} R_{22} J X \\
& =X^{\prime}\left[R_{11}+J^{\prime} R_{21}+R_{12} J+J^{\prime} R_{22} J\right] X \\
& =X^{s} V^{(n+1)} X \text {. }
\end{aligned}
$$

The value function is updated until $V^{(n+1)}$ and $V^{i n '}$ are sufficiently close. The $(1,1)$ element of $V$ tends to converge slowly, but, because it does not enter the first-order conditions $(U Z=0$ ), that element can be ignored when testing for convergence, unless the value function itself is nceded. 